\title{
Web-Based Architecture for Building Management Systems
}

\author{
Gabriela MEHEDINȚU ${ }^{1}$, Camelia Ramona SILVESTRU (BERE) ${ }^{2}$, \\ Cătălin Ionuț SILVESTRU ${ }^{2}$, Vasilica-Cristina ICOCIU ${ }^{3}$ \\ ${ }^{1}$ The Technical University of Civil Engineering of Bucharest \\ ${ }^{2}$ The Bucharest University of Economic Studies \\ ${ }^{3}$ University Politehnica of Bucharest \\ gabriela.mehedintu06@gmail.com,ramona.silvestru@gmail.com, catalin@ase.ro, \\ cvicociu@gmail.com
}

Optimization in terms of functionality, comfort and people's safety, while also ensuring cost minimization may imply automation, including building automation, which can be achieved using Building Management System (BMS). This emerging area is yet to be explored and analyzed, with various approaches in practice, yet little scientific analyses available, especially in terms of system architecture. Based on most frequent functions encountered in office buildings from Romania, we propose a minimal web-based architecture for BMS using modular approach, which enables fast exchange of information among its various components and centralized surveillance of subsystems through minimal human operator intervention. The architecture proposed may be further developed so as to include additional functions in the respective type of building, moreover, such architecture may also be considered for use in buildings with other destinations, taking into account all the characteristics of each building.

Keywords: Building Management System, Infrastructure, Web-based architecture

1 Introduction

Nowadays business is talking about optimization, which can be for example in terms of increase in functionality, comfort and people's safety [1], and cost minimization. These can be achieved by building and equipping buildings with a high degree of automation. In this way, energy savings up to $30 \%$ can be achieved [2], especially in the context of energy consumption in buildings, which accounts for $20-40 \%$ of the energy consumed worldwide [2], [3], [4].

Building automation can be achieved through the Building Management System (BMS), a modular system that allows rapid information exchange between its various components and centralized surveillance of subsystems through minimal human operator intervention [5].

BMS is concept that exists over 30 years and became popular in the past 6-7 years as result of technology expansion for both hardware and software and of the increased accessibility to efficient and user-friendly computer components. [6]
The Building Management System (BMS) is a control system that integrates, monitors and controls signals from more types of mechanical and electrical equipment of a building, such as: lighting and electrical power control, heating, ventilation and air-conditioning (HVAC), security and access control, fire alarm system, elevators etc. [7] The integrated systems can retrieve and send remote signals and commands. [8] It uses controllers, or outstations, (e.g. boilers, pumps, lights, security systems) that exchange information in realtime. [6]

BMS are often used for big buildings, with many equipment and systems, for the main reason to obtain centralized data from the entire field and reduce energy consumption and costs. Because, through this system, it is facilitated a centralized control and monitor of the entire building interior. BMS include also the alarm system, for easier management of emergency situations, everything through a single interface. [9]

The main components are described in the Table 1 
Table 1. Components of BMS [10]

\begin{tabular}{|l|l|}
\hline Components & Examples / Description \\
\hline Field devices & $\begin{array}{l}\text { Temperature, humidity, pressure sensors } \\
\text { Valves, actuators }\end{array}$ \\
\hline Controllers & $\begin{array}{l}\text { Micro-processors } \\
\text { Pre-configured / freely programmable } \\
\text { For the HVAC equipment }\end{array}$ \\
\hline $\begin{array}{l}\text { Centralized workstation } \\
\text { computers }\end{array}$ & $\begin{array}{l}\text { Web servers, } \\
\text { Computers with user-friendly software } \\
\text { Stores databases and provides rapid communication between the } \\
\text { system and the human operator }\end{array}$ \\
\hline
\end{tabular}

Typical systems that are integrated into BMS are Heating, ventilation, and air conditioning (HVAC) and lightning devices (inclusive daylight- or presence-sensitive lightning, sun triggered shading systems etc.), access control systems, fire alarm systems, closed-circuit television (CCTV), window opening system, etc. [11], [12]. The up-to-date and detailed data collected from these integrated systems supports the daily operation of the building [5], [11] and helps in monitoring the resources and react to undesirable situations [1].

Specific features of BMS are:
- State of art controls: accurate algorithms for processing real-time big data;

- Ease of use: supervision of equipment and system through user-friendly software on mobile devices;

- Communication: for grates control of the building;

- Data logging: for trend analysis, building performance and maintenance scheduling, trend data of performance, improved fault finding. [6]

Starting from the created database and how it works, BMS has many advantages and limitations, shown in table 2.

Table 2. Benefits and limitations of BMS

\begin{tabular}{|c|c|c|}
\hline & Benefits & Limitations \\
\hline Generally & $\begin{array}{l}\text { - Consolidated data in a single sys- } \\
\text { tem to improve reporting, infor- } \\
\text { mation management, and decision- } \\
\text { making; } \\
\text { - Fast response to user request; } \\
\text { - Tracking the status of any subsys- } \\
\text { tem; } \\
\rightarrow \text { Reducing risks related to prop- } \\
\text { erty, people and business. }\end{array}$ & $\begin{array}{l}\text { - Permanent active human supervision } \\
\text { of the whole system is not possible, } \\
\text { which may generate the risk of unno- } \\
\text { ticed failures/missing important } \\
\text { events; } \\
\text { - Need of permanent update due to the } \\
\text { constantly developing technology; } \\
\text { - Technical limitations: unable to auto- } \\
\text { mate all desired tasks. }\end{array}$ \\
\hline $\begin{array}{l}\text { Building } \\
\text { owners }\end{array}$ & $\begin{array}{l}\text { - The possibility of charging higher } \\
\text { rents; } \\
\text {-Individual consumption monitor- } \\
\text { ing and billing; } \\
\text { - Effective local and remote control } \\
\text { of different systems in the building; } \\
\text { - Higher life-cycle of the building; } \\
\text { - Immediate monitoring and alert in } \\
\text { case of damage. }\end{array}$ & $\begin{array}{l}\text { - Need of skilled maintenance depart- } \\
\text { ment; } \\
\text { - Financial limitations: high initial in- } \\
\text { vestment value + need for periodic li- } \\
\text { censing; } \\
\text { - Economic limitations: possibility of } \\
\text { higher costs for automate task compared } \\
\text { to manual tasks. }\end{array}$ \\
\hline
\end{tabular}




\begin{tabular}{|l|l|l|}
\hline & Benefits & Limitations \\
\hline $\begin{array}{l}\text { Occupants } \\
\text { of the } \\
\text { building }\end{array}$ & - High degree of comfort; & - High dependence on BMS functional- \\
building's ambient conditions; & - High degree of satisfaction $\rightarrow$ in- \\
creased productivity; & ity; \\
& $\begin{array}{l}\text { - Shorter response times for mal- } \\
\text { functions in relation to a building } \\
\text { without a BMS; } \\
\text { - Financial and time savings for that may have errors. } \\
\text { building maintenance. }\end{array}$ & \\
\hline
\end{tabular}

Source: Authors' own analysis (2018).

As previously mentioned, there is much information available on the advantages of BMS regarding efficiency on technical, economical, small and large (interior and exterior) environmental or productivity level. These subjects are thoroughly defined and analyzed, mostly by the companies that offer such integrates solutions for buildings, more based on practical experience from the market, than on scientific level. [6],[9], [14].

Worldwide, starting around four years ago, topics on energy efficiency became mainstream and many researches were done by technical specialists and companies. The concept of Building Energy Management System was studied and practically developed and documented in scientific literature such as [15], [16], [17], [18], [19], [20].

When we talk about cost efficiency through BMS, we can find in the literature no information. There is only internal analysis of the companies that are interested in investing in BMS, or there is official information on case studies on national and international level, on new or old buildings in which BMS was implemented and is used successfully, such as [21],

The debates regarding productive buildings is still in its early stages, the main conclusion of the studies conducted so far is that the optimization of the overall indoor environment via BMS can increase the productivity by $15 \%$. [22], [23], [24], [25], [29], [17].

BMS is an important tool for optimal use and profitability of a building [26] and operational efficiency of private and public buildings [1], [2].
In Romania, the use of BMS in the public sector is in its early stages of development (airports, hospitals), while in the private sector it is widely used (office buildings, hotels, malls, universities), predominantly in office buildings.

At international level, technical universities approach the subject of BMS, Learning Institutes provide complex courses on how BMS works, private companies provide general information about how BMS works and its benefits (to awaken the interest and need of the client on BMS) and the results of BMS implementation on various case studies ("success stories").

There is insufficient data in the specialized scientific literature regarding BMS, which to provide a complete picture of the field and to be able to offer those interested, an interference with a general or econometric approach to the subject. The few research focus on modern approaches of the technology that BMS works with (e.g. [12]). There are further approaches through case studies (e.g. [5]).

There is no information on minimal architectures, only information about individual applications on certain functions. There is specialized literature on energy efficiency from a technical point of view with economic implications (e.g. [26], [27]); yet we could not identify articles to detailed BMS architectures.

Regarding Romanian scientific studies focused on the national market, we could not identify scientific research studies to approach BMS from a technical (construction or IT) or economic perspective. We can say that there 
are only specific practices, with BMS not approached from a scientific perspective.

Given that the no detailed framework could be identified in the scientific literature with regard to BMS and versions of architecture, we hereby propose a minimal architecture for BMS, taking into consideration the level of existing technological development level and the availability of specific functions within the BMS observed on the market in Romania. The proposed minimum architecture is expected to be adapted to the business interests and the specificities of the functions of the buildings where the BMS is intended to be used.

\section{Methodology}

In order to develop a minimal architecture, the research included two stages: an initial documentation regarding functions in BMS in buildings from Romania, followed by development of the architecture that focuses on functions that have been taken into account more frequently in BMS.

The identification of the more frequent specific functions in Romania was achieved using observation. Thus, we used an observation sheet when analyzing BMS in a number of 20 office buildings in Romania from the urban area. The reason for focusing on urban areas is due to the fact that there is a predisposition for the use of BMS in the urban area, we were unable to identify BMS in the rural area. Moreover, the choice for focusing on the office buildings is grounded on the fact that we could observe that BMS is currently installed mostly in such buildings, as previously mentioned. When observing the BMS in the respective office buildings, focus was on absence/ existence of the function, and on possible information available with regard to complexity that could be observed.

Based on information obtained during the initial documentation stage, in relation to the most frequent functions used in BMS (more than half of the building observed, with addition related to power system, as such system enables the development of the entire system), a minimal architecture is then proposed for building management systems.

\section{Description of building features and pro- posed architecture}

In the 20 office buildings with BMS from Romania, one could observe that several functions were taken into account, as shown in Table 3 .

Table 3. Specific functions in observed buildings

\begin{tabular}{|c|c|c|}
\hline Specific functions & $\begin{array}{l}\text { Number of } \\
\text { buildings that } \\
\text { included the } \\
\text { function }\end{array}$ & $\begin{array}{l}\text { Observations - variations of complexity } \\
\text { identified in the BMS of the observed } \\
\text { buildings }\end{array}$ \\
\hline HVAC & 20 & Automatic / manual control \\
\hline $\begin{array}{l}\text { Fire alarm and safety } \\
\text { system }\end{array}$ & 20 & $\begin{array}{l}\text { With / without direct connection to the Gen- } \\
\text { eral Inspectorate for Emergency Situations }\end{array}$ \\
\hline Access control system & 18 & $\begin{array}{l}\text { Based on: password, PIN, smart card, finger- } \\
\text { print }\end{array}$ \\
\hline Burglar alarms, CCTV & 17 & $\begin{array}{l}\text { Complexity levels could not be checked due } \\
\text { to security reasons }\end{array}$ \\
\hline $\begin{array}{l}\text { Security and observa- } \\
\text { tion system }\end{array}$ & 15 & $\begin{array}{l}\text { Complexity levels could not be checked due } \\
\text { to security reasons }\end{array}$ \\
\hline $\begin{array}{l}\text { Illumination (lighting) } \\
\text { control }\end{array}$ & 14 & $\begin{array}{l}\text { Manual / automatic according to different ex- } \\
\text { ternal factors (e.g. lightning, shading, time) }\end{array}$ \\
\hline Lifts, elevators etc. & 14 & \\
\hline Power system & 8 & \\
\hline $\begin{array}{l}\text { Windows opening sys- } \\
\text { tem }\end{array}$ & 6 & Automatic / manual / no windows opening \\
\hline Plumbing system & 6 & \\
\hline
\end{tabular}




\begin{tabular}{|l|c|l|}
\hline Specific functions & $\begin{array}{l}\text { Number of } \\
\text { buildings that } \\
\text { included the } \\
\text { function }\end{array}$ & $\begin{array}{l}\text { Observations - variations of complexity } \\
\text { identified in the BMS of the observed } \\
\text { buildings }\end{array}$ \\
\hline $\begin{array}{l}\text { Other engineering sys- } \\
\text { tems }\end{array}$ & 5 & \\
\hline Automated parking & 1 & \\
\hline $\begin{array}{l}\text { Public address system } \\
\text { (PA system) }\end{array}$ & 1 & \\
\hline
\end{tabular}

Given the results of the observation, shown in table 3, decision was to focus on functions that were more frequent. Thus, the current BMS analysis focuses on the most common functions that were identified: HVAC, fire alarm and safety system, access control system, burglar alarm and CCTV, security and observation system, lighting control, elevators, to which we added the power systems (as mentioned in the methodology). We propose the architecture presented in figure 1 for the previously-mentioned functions.

The proposed architecture is web-based, given the fact that access via internet implies less costs and possibility for remote access that could be used in managing the system. Moreover, it enables the use of cloud services, through internet-based interfaces, with access to BMS database, while also facilitating the possibility for interaction with several systems, in function of availability and complexity of systems included in the building management system.

The hardware infrastructure includes a BMS server and a BMS web server, while software infrastructure includes a BMS database and a BMS application server. The control center includes BMS workstation, support management and access management, which apply to all functions of the BMS. The architecture is robust; it facilitates the possibility to program the control parameters based on real-time analysis.

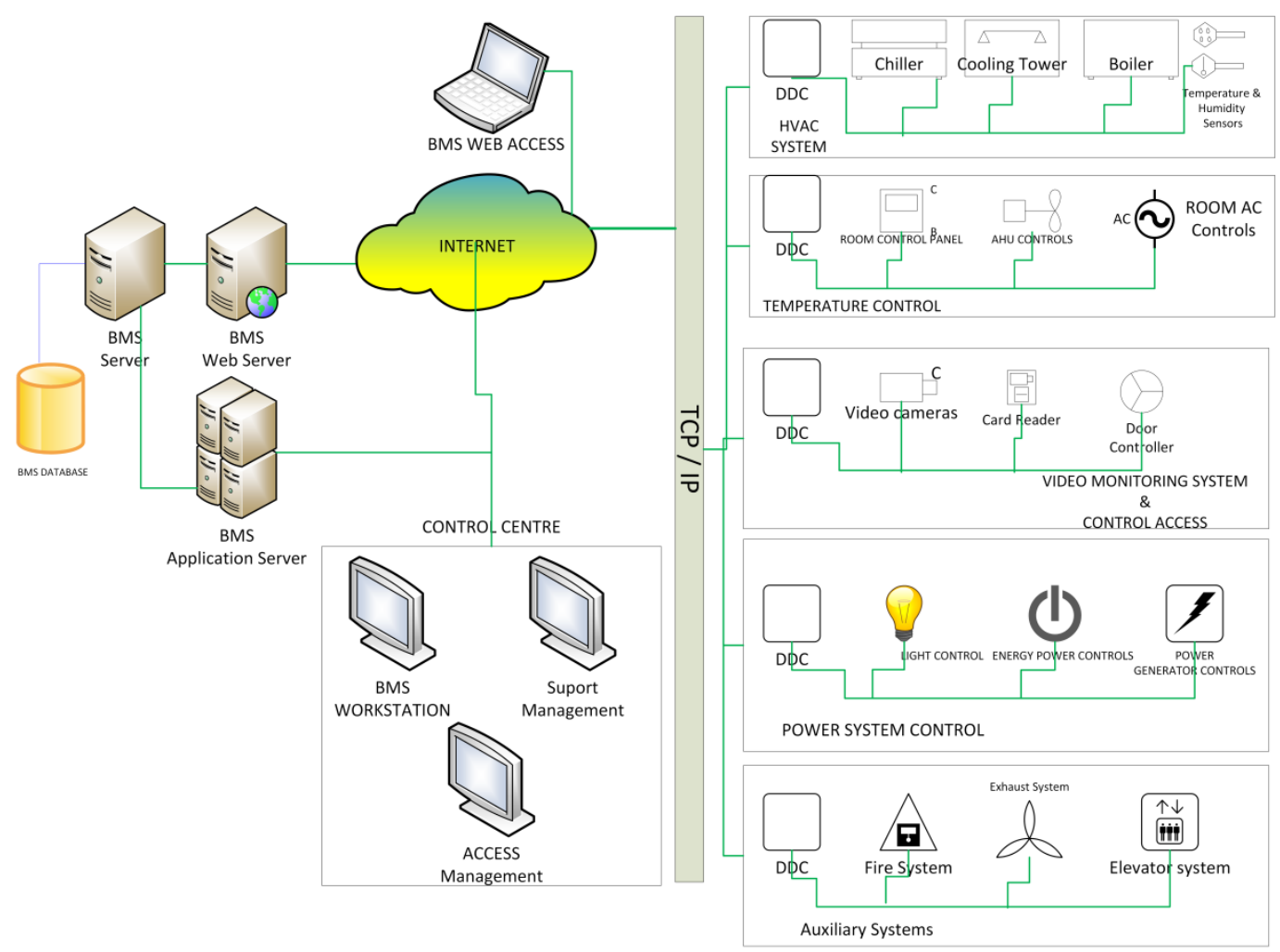

Fig. 1. BMS Architecture 
Upon completion of the project, a fully automated building management system (GA-System), consisting of control stations (servers), operating stations including necessary inputs and outputs, automation devices including MCRL peripherals, all necessary components of building automation infrastructure, switching cabinets for computerization and power supply communications, camera automation systems (individual room controllers) as well as the interfaces needed to connect to other systems, such as safety management, M-bus connections, etc. This will include all necessary software, including operating licenses, including co-operation with other subcontractors for commissioning, verification, documentation preparation.

All building elements, components, units and functions of the automated building management system shall be performed in accordance with national regulations, with applicable technical standards and procedures.

The essential requirements for the building automation system (GA-System) are:

- Server-based control station with appropriate memory and disk capacity, and accompanying operating system (e.g. Windows Server $\mathrm{xxxx}$ ); joint server (latest generation) for all the buildings of the project at hand;

- PC-based operating stations with appropriate memory and disk capacity, and accompanying operating system (e. g. Windows 10) and Office package as member within the automation network (e.g. Ethernet with TCP/IP);

- Mobile operating station (notebook) for local system operation;

- I/O units such as printers, monitors, keyboards, input devices based on standard IT components;

- Simple system operation in English, switchable to and/or selectable for the country's language with appropriate authorization hierarchies, access rights (via password and user code);

- Monitoring and optimization functions;
- Dynamic graphic facility/system representation (reaction time $<2$ seconds upon invocation or change of status at the periphery) at operating stations including creation of dynamic facility images;

- Comprehensive logging and data analysis options, data export into spreadsheet or database program (historical data);

- Comprehensive alarm management with alarm routing function, alarm forwarding via SMS and/or e-mail;

- Remote operation of the building automation system (GA-System) via web browser and Intranet/Internet;

- Open database structure;

- Interface to SMS system (safety management system) via OPC (Open Platform Communications);

- DDC- (Digital Dial Controller) and PLC (Programmable Logic Controller) functions of the automation devices;

- Autonomous/independent function of the automation devices;

- Control/process response time $<2$ seconds;

- Direct communication automation device to automation device;

- Emergency operation level in the I/O modules of the automation devices;

- Free choice of addressing for data points (AK-System); similar address structure for all buildings/construction components;

- Energy optimization functions;

- Expandability on the management level (e.g. additional operating stations), and the automation level, as well as the field level (e.g. additional buildings/building components);

- Integrated room automation system with standardized normed data protocol;

- M-Bus interface(s) for data transfer to energy meters;

- Modbus interface for data transfer from energy analysis devices;

- OPC interface. 
All basic function, processing function, enhanced processing functions, except for maintenance management and voice connections, are included via I\&C system / building management (MCR/GA) and room automation system in accordance with VDI 3814 for all BTAs. In addition, included in the MCR/GA work are also all functions that go beyond those listed in the VDI that are described and specified in the work/facility description of the individual buildings and/or BTAs.

The central facilities are located on this level, i.e. the interface between the user and the system. It is here that communication takes place (also data and log requests, command input, parameterization programming, etc.) as well as data processing and storage.

The management level consists of:

- Control/Operating computer as server or for 19" rack mounting (based on customer's choice);

- Graphical color operating station;

- $\quad$ 15" TFT color monitor for server, 19" TFT color monitor for operating station;

- Keyboard, pointing device (mouse), etc.;

- Mobile graphical color operating station in form of a notebook with the following minimum specifications;

- Graphical log printer as A4 color laser printer, network capable;

- Alarm printer 2 color (red/black) matrix printer for fanfold paper, network capable or print server;

- UPS system(s) for control operating computer and/or graphical color operating station (at least $30 \mathrm{~min}$. runtime);

- Network infrastructure components for building automation(GA) network(s).

The central facilities are suited for data processing, data storage, system operation, visualization, as well as for entering all necessary parameters for new and re-projecting (structuring, parameterization, programming) of the processes and the functions in accordance with the requirements, up-/download function from/to the automation devices, safety automation device data, additionally for display, control and analysis of the data transmitted from the integrated room automation system, the M-bus system, data via Modbus or the OPC interface. The system operation is performed via a menu driven graphical user interface with integrated online help function, either via dynamic facility images or in text/table form and/or also in a combination of both formats, supported by clear text for statistic and measured data as well as supplemental and instruction texts. Data access is protected via password system, where staggered hierarchy levels are available.

\section{The automation level}

The automation devices (AutoGer) are located on the automation level. Automation devices are autonomous, independently operational systems with all necessary interfaces, capable of communicating with each other and with the central facilities, with resident programs, suitable for all control algorithms, calculation, optimization and monitoring tasks as well as control tasks. Definable time and event programs, automatic switch from summer to winter time and vice versa. Each automation device is equipped with an event buffer memory in which the events that occurred last are stored with date and time, point description and point status. The automation devices are suitable for reading of function and application programs and/or parameters via media and/or interfaces or network connections; stored data and programs are protected against power outage.

The complete software required for the BA system is included in the MCR/BA service description. The software consists of:

- Operating system(s)/company ware including user licenses;

- Software for central operation and monitoring installations (user entitlements, historical data, trend records, data storage etc.);

- Software for communications/data transfers/network(s);

- Software for interfaces, input/output equipment, data security etc.;

- Software for function programs (software for the required control, regulation, monitoring and optimization functions); 
- Software for the integrated room automation system;

- Software for data display, storage and analysis from the M-bus system;

- Software for communications with other systems;

- Software for data communication via BACnet (expansion option).

Given the internet web-based approach, standardized network communication protocols have been included, enabling also appropriate levels of quality assurance.

Each of the functions taken into consideration have been approached, in terms of hardware and/or control for each of the respective functions. The modular approach in BMS architecture proposed enables integration of equipment from different producers, making them function in unitary integrated way. Further developments of this architecture is possible, with detailing of components, while also taking into account technical specifications in relation to the building and to the hardware and software infrastructures available.

The proposed system was developed taking into account the option of reduced human presence and / or intervention. Thus, the internet web-based approach in architecture that has been proposed, with control center designed so as to include access either in the building, yet also with web access, enables the management of the building with little involvement of human resource present on site, facilitating the detection, the prevention of specific problems almost in real time, while also enabling remote interventions in case of need, which thus reduces significantly the duration for interventions in case of need.

\section{Conclusions}

When approaching the issue of building automation, using Building Management System (BMS), we focused on developments in this emerging area, taking into account the fact that no detailed framework in literature could be identified, especially in relation to possible architectures for BMS.

We proposed a minimal architecture for BMS, which is internet web-based, with possible use of cloud services. Functions taken into consideration in designing this architecture were selected based on most frequent functions encountered in office buildings from Romania. Limitations of the architecture proposed may be due to number of functions approached, as functions of interest for BMS may vary over time and expand. Yet, we expect that most of the functions approached in the proposed architecture may become taken for granted, with other functions being added; moreover, the level of complexity in approaching specific functions may vary, requiring further developments into what is considered as minimal architecture to be taken into account. Technical specifications for hardware may pose limitations when applying the proposed architecture, given technological progress and life span of hardware.

The architecture proposed may be further developed so as to include additional functions in the respective type of building, moreover, such architecture may also be considered for use in buildings with other destinations, taking into account the characteristics of each building and the functions concerned.

\section{References}

[1] I. Pukite, I. Geipele, "Different Approaches to Building Management and maintenance Meaning Explanation", in Procedia Engineering, vol. 172, pp. 905912, 2017. ISSN 1877-7058. Available: http://www.sciencedirect.com/science/article/pii/S1877705817306057. [Accessed: May 11, 2018].

[2] S. Papantoniou, S. Mangili, I. Mangialenti, "Using Intelligent Building Energy Management System for the Integration of Several Systems to one Overall Monitoring and Management System,", in Energy Procedia, vol. 111, pp. 639-647, 2017. ISSN 1876-6102. Available: http://www.sciencedirect.com/science/article/pii/S1876610217302564. [Accessed: May 10, 2018].

[3] L. Linder, D. Vionnet, J.-Ph. Bacher, J. Hennbert, "Big Building Data - a Big Data Platform for Smart Buildings", in Energy Procedia, vol. 122, pp. 589-594, 2017. 
ISSN 1876-6102. Available: http://www.sciencedirect.com/science/article/pii/S1876610217329582. [Accessed: May 11, 2018].

[4] G. Bovet, J. Hennebert, "Will web technologies impact on building automation systems architecture?" in Procedia Computer Science, vol. 32, pp. 985-990, 2014. ISSN 1877-0509. Available: http://www.sciencedirect.com/science/article/pii/S1877050914007224. [Accessed May 10,, 2018].

[5] A. Kucera, T. Pitner, "Semantic BMS: Allowing usage of building automation data in facility benchmarking", in Advanced Engineering Informatics 35, pp. 69-84, 2018. Available: http://www.sciencedirect.com/science/article/pii/S147403461730023X. [Accessed May 10, 2018].

[6] DETR Environment Transport Regions, "Building management system in further and higher education". [Online]. Available: https://www.cibse.org/getmedia/02efe17e-5efe-4171-b272c5e2c10c53ce/GPG246-Building-Management-Systems-in-Further-and-HigherEducation-(1998).pdf.aspx [Accessed June 24, 2018].

[7] A. Smith, "Building Management System: Seminar 1 - The Basics Explained". [Online]. Available: https://www.melbourne.vic.gov.au/SiteCollectionDocuments/bms-the-basics-explained.pdf. [Accessed June 23, 2018].

[8] Carel, „Building Management System“. [Online]. Available: http://www.carel.com/bms-building-management-system-interface. [Accessed May 23, 2018].

[9] Advanced Control Corporation, "Building Management System", April 8, 2016. [Online],. Available: http://advancedcontrolcorp.com/blog/2016/04/building-management-system/. [Accessed June 30, 2018].

[10] Honeywell. An Overview to BMS. [Online]. Available: http://www.sau.ac.me/ENERESE/BMSO verview.pdf. [Accessed March 23, 2018].
[11] J. Nembrini, F. Evequoz, R. Baeriswyl, D. Lalanne, "Advocation the use of visual analytics in the context of BMS data", in Energy Procedia, vol.122, pp. 715-720, 2017. ISSN 1876-6102. Available: http://www.sciencedirect.com/science/article/pii/S1876610217329892. [Accessed 10 May, 2018].

[12] A. Kucera, P. Glos, T. Pitner, "Fault Detection in Building management system networks", in IFAC Proceedings Volumes, pp. 416-421,2013. ISSN 1474-6670. Available: http://www.sciencedirect.com/science/article/pii/S1474667015373638. [Accessed 14 May, 2018].

[14] KMC Controls, "What are Benefits of a BAS?". [Online]. Available: https://www.kmccontrols.com/blog/144what-are-benefits-of-a-bas. [Accessed 28 June, 2018].

[15] T.Yang, D. Clements, C. M. Marson, "Building Energy Management Systems", in Encyclopedia of Sustainable Technologies, Elsevier, pp. 291-309, 2017, ISBN $9780128047927 . \quad$ Available: http://www.sciencedirect.com/science/article/pii/B978012409548910199X. [Accessed June 19, 2018].

[16] D.Bonillaa, M. G. Samaniegob, R. Ramosa, H. Campbella, "Practical and lowcost monitoring tool for building energy management systems using virtual instrumentation", in Sustainable Cities and Society, vol. 39, pp. 155-162, May 2018. ISSN 2210-6707. Available: http://www.sciencedirect.com/science/article/pii/S2210670717308788. [Accessed June 19, 2018].

[17] S. Rotger-Griful, U. Welling, R. H. Jacobsen, "Implementation of a building energy management system for residential demand response", in Microprocessors and Microsystems, vol. 55, pp. 100-110, November 2017. ISSN 0141-9331. Available: http://www.sciencedirect.com/science/article/pii/S0141933116303696. [Accessed June 18, 2018]. 
[18] M. Macarulla, M. Casals, N. Forcada, M.Gangolells, "Implementation of predictive control in a commercial building energy management system using neural networks", in Energy and Buildings, vol.151, pp. 511-519, 15 September 2017. ISSN 0378-7788. Available: http://www.sciencedirect.com/science/article/pii/S0378778817300907. [Accessed June 18, 2018].

[19] W. El-Baz, J. Honold, L. Hardi, P. Tzscheutschler, "High-resolution dataset for building energy management systems applications", in Data in Brief, vol. 17, pp. 157-161, April 2018. ISSN 2352-3409. Available: http://www.sciencedirect.com/science/article/pii/S2352340917307539. [Accessed June 18, 2018].

[20] N. Haidar et al., "New consumer-dependent energy management system to reduce cost and carbon impact in smart buildings", in Sustainable Cities and Society, vol. 39, pp. 740-750, May 2018. Available: http://www.sciencedirect.com/science/article/pii/S2210670717307047. [Accessed June 18, 2018].

[21] C. Holbeck, "Maximizing ROI in an Integrated BMS" in Buildigs Smarter Facility Management, 11 January, 2007. [Online], Available: https://www.buildings.com/article-details/articleid/5411/title/maximizing-roi-in-an-integrated-bms. [Accessed June 28, 2018].

[22] J. Giarrusso, "Don't Underestimate the Impact of Employee Comfort or Employee Productivity in your Office Building", October 20, 2015, [Online]. Available https://blog.schneider-electric.com/building-management/2015/10/20/dont-under- estimate-impact-employee-comfort-employee-productivity-office-building/. [Accessed June 28, 2018].

[23] JGID BMS, "How Business Management Software Improves Productivity", January 23, 2017. [Online]. Available https://www.jgid.com/management-software-improve-productivity/. [Accessed June 28, 2018].

[24] Sodexo, "Improving Indoor Environments To Increase Productivity By 15\%". [Online], Available http://www.qualityoflifeobserver.com/sites/default/files/sodexo_whitepaper_fm_productivity_en.pdf. [Accessed June 14, 2018].

[25] H. Juslen, M. Fassian, Philips AEG Light $\mathrm{GmbH}$, „Beleuchtung, Produktivität und Wohlbefinden - wissenschaftliche Studien in industrieller Umgebung", presented at Licht 2004, Dortmund.

[25] A. Redlein, V. Seibert-Giller, O. Markovic, C. Humhal, M. Zobl, „Produktivität von MitarbeiterInnen und wie Arbeitsplätze diese beeinflussen / Studie Optimierte Unterrichtsräume in Kärtner Pflichtschulen“, Vienna, 2014.

[26] T. Buus, "Energy efficiency and energy prices: A general mathematical framework", in Energy, vol. 139, pp. 743-754, November 2017. ISSN 0360-5442. Available: https://www.sciencedirect.com/science/article/pii/S0360544217313439. [Accessed 15 June, 2018].

[27] I. El-Darwish, M. Gomaa, "Retrofitting strategy for building envelopes to achieve energy efficiency", in Alexandria Engineering Journal, vol. 56, issue 4, pp. 579589, December 2017. ISSN 1110-0168. Available: https://www.sciencedirect.com/science/article/pii/S1110016817301734. [Accessed 15 June, 2018].

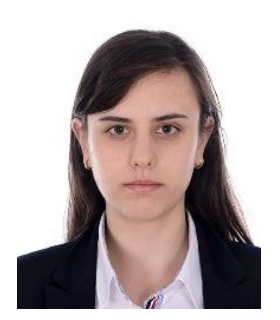

Gabriela MEHEDINŢU received the B.S. and M.S. degrees in Economics from The Bucharest University of Economic Studies in 2012 and 2014. Now she graduated the $\mathrm{PhD}$ at the Technical University of Civil Engineering Bucharest. She is interested in the new field of facility management, therefore she participated at numerous international conferences on this topic and at an Erasmus+ Scholarship, to extend her area of expertise. Her work is focused on building technologies, software application, integrated management systems. 


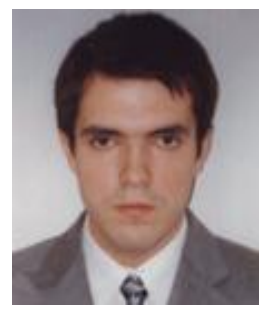

Cătălin Ionuț SILVESTRU is assistant professor in Economic Informatics and Cybernetics Department, Academy of Economic Studies of Bucharest. He published over 60 articles in journals and magazines in computer science, informatics, e-learning, project management and long life learning fields, over 40 papers presented at national and international conferences, symposiums and work-shops and he was member over thirty-eight research projects. He received his $\mathrm{PhD}$ in the field of Economic Informatics at the Academy of Economic Studies. He is a member of INFOREC professional association, Project Management Romania association, ACM, IEEE and others. He has one invention and one prototype approved. His work focuses on the programming, information system, e-learning, long life learning, project management, building management system, software application, integrated management systems and human resources development.

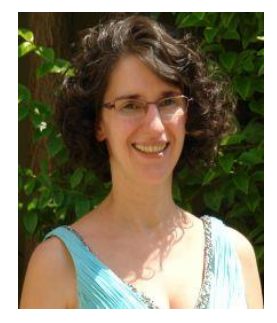

Ramona Camelia SILVESTRU (BERE) holds a PhD diploma in Economics. She published articles in journals and magazines in public administration, computer science, informatics, e-learning, project management and long life learning fields, over 15 papers presented at international conferences, symposiums and work-shops and she was member two research projects. She is a member of ACM professional association. Her work focuses on public policies, urban and regional development, public administration, human resource development, e-learning, long life learning, software application, integrated management systems and project management.

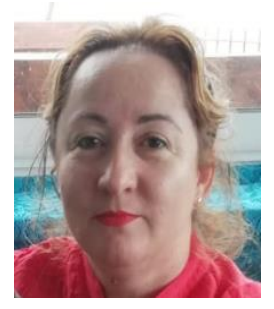

Cristina Vasilica ICOCIU graduated the Faculty of Law in 1996 with a Bachelor diploma at the Alexandru Ion Cuza Police Academy. She holds a Master diploma since 2001 and a PhD diploma since 2010, both in administrative sciences at the National School of Political Studies and Public Administration. In this respect she has an extensive experience in central admin-istration field, mainly in education and research field, where she has occupied various man-agement positions, from General Manager to Deputy Secretary-General, but also at govern-ment level, as councillor to the Vice prime-minister on economy and business environment. Alongside the activities carried out in the public administration sector, Mrs. Icociu has also been active in the academic field, first as associate professor at the Technical University of Civil Engineering of Bucharest/ University Politehnica of Bucharest and the National School of Political Studies and Public Administration. Since 2012 she holds the position of Lecturer at the University Politehnica of Bucharest, the Faculty of Entrepreneurship, Business Engineering and Management, Department of Economical Engineering where she is teaching various subjects from the field of legal sciences relevant for engineers. She has also worked in writing and implementing staged of several European financing projects as legal advisor or project manager. She co-authored 5 books and 13 articles and has also participated in the elaboration of several laws, ordinances, government decisions and other central public admin-istration acts. She is very diligent about the quality of the works, being interested in compli-ance to the human rights, equal opportunities, academic ethics and integrity. 